\title{
Large inter- and intra-case variability of first generation tau PET ligand binding in neurodegenerative dementias
}

\author{
Melissa C. Wren ${ }^{1,2}$, Tammaryn Lashley ${ }^{2}$, Erik Årstad ${ }^{1}$ and Kerstin Sander ${ }^{1,3^{*}}$ (D)
}

\begin{abstract}
Imaging of pathological tau with positron emission tomography (PET) has the potential to allow early diagnosis of the dementias and monitoring of disease progression, including assessment of therapeutic interventions, in vivo. The first generation of tau PET tracers, including the carbazole flortaucipir and the 2-arylquinolines of the THK series, are now used in clinical research; however, concerns have been raised about off-target binding and low sensitivity. With the aim to determine the nature of tau pathology depicted by structurally distinct tau ligands we carried out a microscopic neuropathological evaluation in post-mortem human brain tissue of cases with primary and secondary tauopathies. Carbazole and 2-arylquinoline binding was only observed in cases with Alzheimer's disease and one case with frontotemporal dementia and parkinsonism linked to chromosome 17 exhibiting a R406W MAPT mutation. In end stage Alzheimer's disease cases, fluorescent imaging with the carbazole T726 and the 2-arylquinoline THK-5117 revealed high inter- and intra-case variability of tracer binding, and this was corroborated by quantitative phosphorimaging with the PET tracer $\left[{ }^{18} \mathrm{~F}\right]$ THK-5117. Microscopic analysis of the pathological inclusions revealed that the fluorescent tracers preferentially bind to premature tau aggregates. Whilst T726 binding was limited to neuronal tau, THK-5117 additionally depicted neuritic tau. Neither tracer depicted tau in pre-symptomatic disease.

Our results highlight limitations of the first generation of tau PET tracers, in particular lack of correlation between pathological tau load and tracer binding, limited sensitivity to tau in early disease, and high variability in tracer binding between and within cases. Concerns remain that these limitations may also affect the next generation tracers as they target the same high affinity binding site. Therefore, it is crucial to assess inter- and intra-subject correlation of tracer binding with pathological tau load in post-mortem tissue studies, and to rigorously assess novel tau PET tracers before translation into clinical studies.
\end{abstract}

Keywords: Flortaucipir, THK, Positron emission tomography, Alzheimer's disease, Tauopathy

\section{Introduction}

Dementia represents one of the most pressing public health challenges worldwide. A clinical diagnosis of the underlying disease causing the dementia remains challenging, particularly at the early stages, and a definite confirmation is usually only obtained post-mortem through histopathological examination of the brain.

Approximately $80 \%$ of dementia cases are associated with structural changes of the microtubule associated

\footnotetext{
* Correspondence: k.sander@ucl.ac.uk

${ }^{1}$ Institute of Nuclear Medicine and Department of Chemistry, University College London, London, UK

${ }^{3}$ Radiochemistry, University College London, Kathleen Lonsdale Building, 5 Gower Place, London WC1E 6BS, UK

Full list of author information is available at the end of the article
}

protein tau (MAPT), causing defective tau to aggregate in neurons and glial cells [48]. The shape and distribution of these inclusions are characteristic for the respective subtypes of tauopathy. In Alzheimer's disease, the most common dementia (50-70\% of all clinical diagnoses), pathological tau load correlates closely with cognitive decline, suggesting that tau is a suitable biomarker for monitoring of disease progression [1, 14]. Quantitative assessment of tau pathology in vivo would have significant implications for medical research and for clinical practice, as it could potentially improve clinical diagnosis, predict disease progression, facilitate patient stratification and provide an outcome measure for putative diseasemodifying interventions. 
The first generation of tau selective ligands for noninvasive imaging with positron emission tomography (PET) have recently entered clinical studies. The clinically most advanced compound $\left[{ }^{18} \mathrm{~F}\right]$ flortaucipir (formerly known as $\left[{ }^{18} \mathrm{~F}\right] \mathrm{AV}-1451$ or $\left.\left[{ }^{18} \mathrm{~F}\right] \mathrm{T} 807\right)$, alongside the derivative $\left[{ }^{18} \mathrm{~F}\right] \mathrm{T} 808$ and the fluorescent analogue T726, belong to the structural class of carbazoles, whereas the different compounds of the THK series $\left(\left[{ }^{18} \mathrm{~F}\right]\right.$ THK-5105, $\left[{ }^{18} \mathrm{~F}\right] \mathrm{THK}-$ 5117 and $\left.\left[{ }^{18} \mathrm{~F}\right] \mathrm{THK}-5351\right)$ contain a 2 -arylquinoline core. In patient studies, PET tracers from both compound classes have been reported to be suitable for staging of Alzheimer's disease [30, 39, 40], and for differential diagnosis of Alzheimer's disease and progressive supranuclear palsy [33, 47]. Some of these findings, in particular tracer binding to primary tauopathies, remain controversial, and are not supported by ex vivo studies on post-mortem brain tissue $[13,16,22,23,29,31,37]$. Furthermore, the first generation of tau PET tracers suffer from off-target binding, and in patient populations, where a signal is obtained, the sensitivity may be low $[3,36]$. Efforts to develop and evaluate the next generation of tau selective tracers are ongoing $[9,15]$. Pilot PET imaging studies with recently reported compounds, such as RO6958948, MK-6240 and PI-2620, suggest that these may have improved sensitivity and specificity for monitoring tau pathology in vivo. Yet, some, if not all, of the second generation tau ligands disclosed to-date display close structural similarities, and have an overlapping binding site with the first generation tau tracers. This highlights the importance of elucidating the interplay between the T808 binding site [50] and tau pathology.

We previously assessed binding of $\left[{ }^{18} \mathrm{~F}\right]$ flortaucipir, a structural analogue of T808, to human post-mortem brain tissue from cases with Alzheimer's disease and primary tauopathies, and observed a lack of correlation between PET tracer binding and total pathological tau load in the frontal and temporal cortices [37]. We also found evidence for tracer binding to a non-tau binding site. It has now been confirmed that flortaucipir exhibits strong off-target binding to monoamine oxidase isoforms and pigment containing cells, predominantly expressed in the striatum and the substantia nigra, respectively $[15,23,46]$. A similar off-target binding profile has been demonstrated for the compounds of the THK series [28, 31]. However, this does not fully explain the discrepancy between tracer binding and total tau load in the cortical brain areas.

The macroscopically observed lack of correlation between $\left[{ }^{18} \mathrm{~F}\right]$ flortaucipir binding and total tau load [37] prompted us to investigate what tau tracers depict on a cellular level. With the aim of determining whether this discrepancy can be attributed to the binding properties of specific compounds, different compound classes, or to the tau binding site(s), we carried out a microscopic neuropathological evaluation in post-mortem human brain tissue of cases with Alzheimer's disease, a range of primary tauopathies and non-demented controls with and without tau pathology. We used a combination of histology and nuclear imaging techniques to reveal ligand-tau interaction in a qualitative as well as in a quantitative manner. In particular, we aimed to answer the following questions: 1) what is the nature of tau pathology that the first generation tau ligands depict in vivo; 2) do carbazoles and 2-arylquinolines differ in their binding profiles; 3 ) is the T808 binding site an appropriate target for the development of tau PET tracers?

\section{Materials and methods}

\section{Experimental design}

Tau selective ligands were chosen to cover the most prominent compound classes of the first generation of tau PET tracers. We included the carbazoles flortaucipir and T726 as well as the 2-arylquinoline THK-5117, which is inherently fluorescent. As flortaucipir is not inherently fluorescent, we used the fluorescent structural analogue T726. T726 was used for screening purposes in the development process of flortaucipir and was shown to target the same tau binding site as flortaucipir [49]. We carried out a histopathological evaluation in human post-mortem brain tissue from neuropathologically well-characterised cases, selected to cover a range of tauopathies as well as controls (cf. 'Case selection' below). In order to assess the nature of tau pathology that the different compound classes depict, we used fluorescence microscopy with T726 and THK-5117 in conjunction with immunofluorescence. Where further clarification of tau ligand binding was required (THK-5117 binding to plaque like structures; vide infra), high resolution autoradiography in conjunction with immunohistochemistry was carried out. Due to the high concentration of fluorescent tau ligands needed for imaging experiments, we corroborated our results using quantitative phosphorimaging. PET tracer $\left[{ }^{18} \mathrm{~F}\right] \mathrm{THK}-5117$ binding was carried out at nanomolar concentrations that would be relevant for in vivo imaging.

\section{Case selection}

We evaluated tissue from brains donated for research to the Queen Square Brain Bank for Neurological Disorders, Institute of Neurology, University College London. All cases had undergone standard neuropathological assessment and were diagnosed according to standard criteria. Demographic data are summarised in Table 1, and additional information on tissue processing can be found in the Additional file 1: Table S1.

Controls were cases without a clinical history of dementia, psychiatric or neurological diseases at the time of brain donation to the Queen Square Brain Bank. Although not showing any signs of cognitive impairment at the time of death, control cases can have a 
Table 1 Demographic Data of Cases Included in the Study

\begin{tabular}{|c|c|c|c|c|c|c|c|}
\hline Case & Sex & AAO & AAD & Brain Weight (g) & Braak Stage & Thal Phase & ABC Score \\
\hline CTRL1 & $\mathrm{F}$ & - & 68 & 1330 & 0 & 0 & AOBOCO \\
\hline CTRL2 & M & - & 71 & 1480 & । & 0 & $\mathrm{AOB} 1 \mathrm{CO}$ \\
\hline CTRL3 & $\mathrm{F}$ & - & 80 & 1242 & $\|$ & 0 & $\mathrm{AOB1C0}$ \\
\hline CTRL4 & M & - & 89 & 1448 & III & 3 & $\mathrm{~A} 2 \mathrm{~B} 2 \mathrm{C} 1$ \\
\hline AD1 & $\mathrm{F}$ & 50 & 66 & 906 & $\mathrm{Vl}$ & 5 & A3B3C3 \\
\hline AD2 & M & 63 & 73 & 1269 & $\mathrm{Vl}$ & 5 & A3B3C3 \\
\hline AD3 & M & 52 & 68 & 1234 & $\mathrm{VI}$ & 5 & A3B3C3 \\
\hline AD4 & M & 63 & 74 & 1022 & $\mathrm{Vl}$ & 5 & A3B3C3 \\
\hline FTDP1 $^{\text {a) }}$ & M & 55 & 66 & 1208 & 0 & 0 & AOBOCO \\
\hline FTDP2 $2^{\text {b) }}$ & M & 68 & 74 & 1048 & $\|$ & 2 & $\mathrm{~A} 1 \mathrm{~B} 1 \mathrm{C} 1$ \\
\hline FTDP3 ${ }^{\mathrm{C})}$ & M & 59 & 66 & 1399 & 0 & 0 & AOBOCO \\
\hline PICK1 & M & 57 & 62 & 1166 & III & 1 & $\mathrm{~A} 1 \mathrm{~B} 2 \mathrm{C} 1$ \\
\hline PICK2 & M & 54 & 64 & 1040 & 0 & 3 & $\mathrm{~A} 2 \mathrm{~B} 0 \mathrm{C} 1$ \\
\hline PSP1 & M & 62 & 74 & 1580 & 0 & 2 & $\mathrm{~A} 1 \mathrm{~B} 0 \mathrm{C} 1$ \\
\hline PSP2 & $\mathrm{F}$ & 60 & 68 & 1177 & 0 & 1 & $\mathrm{~A} 1 \mathrm{~B} 0 \mathrm{C} 1$ \\
\hline CBD & $\mathrm{F}$ & 62 & 69 & 1100 & 0 & 0 & AOBOCO \\
\hline
\end{tabular}

Abbreviations: CTRL, control; AD, Alzheimer's disease; FTDP, frontotemporal dementia with parkinsonism linked to chromosome 17; PICK, Pick's disease; PSP, progressive supranuclear palsy; $C B D$, corticobasal degeneration; MAPT, microtubule associated protein tau gene locus; $M / F$, male/female; $A A O$, age at onset; $A A D$, age at death

Genetic variants: a) MAPT R406W; b) MAPT $\Delta 280 \mathrm{~K}$; c) MAPT $10+16$

considerable burden of amyloid and tau pathology (up to Thal phase 4 and Braak \& Brak stage IV, respectively). The control cases included in our study had absent pathology (CTRL1), or low levels of tau and/or amyloid pathology (Braak \& Braak tau stage I-III and Thal phase 1-3; CTRL 2-4). All cases with neurodegenerative diseases had dementia in life. The selected Alzheimer's disease cases showed a high neuropathological change (CERAD frequent neuritic plaques, Braak \& Braak tau stage VI and Thal phase 5 amyloid plaque pathology) using the National Institute on AgingAlzheimer's Association guidelines [4, 25, 26, 44]. Differential diagnosis of the FTLD-tau cases was carried out following the criteria described by the consortium for Frontotemporal Lobar Degeneration [8]. The chosen FTDP-17 cases included exonic MAPT mutation variants (R406W and $\triangle 280 \mathrm{~K}$ ), and one case with an intronic $10+16$ MAPT mutation. Brain areas in the disease cases were selected due to the presence of abundant tau deposits. Frontal and temporal cortices as well as the hippocampus were examined in Alzheimer's disease, FTDP-17 and control cases. Frontal and temporal cortices were examined in Pick's disease, frontal cortex and cerebellum in progressive supranuclear palsy, and frontal and parietal cortex in corticobasal degeneration. The frontal area used corresponded to Brodman area 9, the temporal cortex and hippocampus were taken from the level of the lateral geniculate body. The choroid plexus was not attached to the hippocampus. Cerebellum sections contained cerebellar folia as well as white matter exhibiting the dentate nuclei. Parietal cortex samples were taken from the superior parietal lobule.

\section{Immunohistochemistry on flash frozen tissue sections}

Immunohistochemistry staining was carried out in flash frozen tissue on sequential sections to those used for autoradiography and fluorescence imaging. Tissue sections were cryosectioned at $10 \mu \mathrm{m}$, mounted on superfrost microscope slides and post-fixed in $4 \%$ paraformaldehyde for $30 \mathrm{~min}$. Endogenous peroxidase activity was blocked using $0.3 \%$ hydrogen peroxide in methanol $(10 \mathrm{~min}$, room temperature). Non-specific binding was blocked and tissue permeabilised, using 10\% dried non-fat milk under addition of $0.3 \%$ Triton $\mathrm{X}-100 \quad(30 \mathrm{~min}$, room temperature). Tissue sections were incubated with either AT8 (Thermoscientific, 1:600) or A $\beta$-XP (Cell Signaling, 1:200) for one hour at room temperature, followed by biotinylated anti-mouse or anti-rabbit IgG (DAKO, 1:200; $30 \mathrm{~min}$ ), respectively, and avidin-biotin complex (Vector Laboratories; $30 \mathrm{~min}$ ). Colour was developed with 3,3'-diaminobenzidine and hydrogen peroxide. Counterstaining was carried out using Mayer's haematoxylin.

Pathological phosphorylated tau burden was detected using AT8 immunostaining. AT8 recognises the two earliest phosphorylation sites on tau and highlights all levels of neurofibrillary pathology, including intra- and extracellular tangles, pre-tangles and neuropil threads [10]. Similarly, the amyloid antibody A $\beta$-XP detects 
several isoforms of amyloid beta, including the pathogenic species A $\beta-42$. Moreover, the combination of AT8 (raised in mouse) and A $\beta$-XP (raised in rabbit) allowed double immunofluorescence staining to be carried out [51]. Immunostained slides were scanned on an Aperio ScanScope slide scanner, producing high resolution digital histology images. Regions of interest were extracted using Aperio ImageScope software. Image quantification was performed using the analysis software packages ImageJ (version 1.48) [38] and Python (version 3.6.1). Macroinstructions processing of immunohistochemistry images was conducted firstly by random box generation of 10 squares within a dedicated region of interest, and secondly by setting thresholds for the 3,3'diaminobenzidine chromogen. Tau load was quantified in adjacent sections to those exposed to $\left[{ }^{18} \mathrm{~F}\right] \mathrm{THK}-5117$, as percentage of positively stained tissue detected in regions of interest.

\section{Fluorescence microscopy}

Tissue cryosections $(10 \mu \mathrm{m})$ on superfrost microscope slides were post-fixed in $4 \%$ paraformaldehyde for $30 \mathrm{~min}$. Autofluorescence was largely quenched by treating the sections with sudan black $(0.1 \%$ in $70 \%$ ethanol) for ten minutes, followed by washing with $30 \%$ ethanol and tris buffered saline containing 0.05\% Tween 20 .

\section{Fluorescent tau ligand binding studies}

Non-specific binding was blocked and tissue permeabilised, using $10 \%$ dried non-fat milk under addition of 0 . 3\% Triton X-100 (30 min, room temperature) [19]. Sections were incubated with either T726 $(100 \mu \mathrm{M})$ [49] or THK-5117 $(100 \mu \mathrm{M})$ [29] for one hour at room temperature, in a humidified chamber and under exclusion of light. Sections incubated with T726 were mounted with DAPI-containing fluorescent mounting medium (Vector Laboratories), and sections with THK5117 were incubated with Nissl Neurotrace 640 (Molecular Probes; 1:100 for $20 \mathrm{~min}$ ) to highlight neuronal nuclei within tissue samples.

The use of blocking buffer (composed of milk and Triton $\mathrm{X}-100$ ) did not affect the binding of the fluorescent small molecule tau ligands (control experiments not shown), yet it helped to reduce auto fluorescence of the basal tissue extracellular matrix. In addition, comparability of results obtained from experiments in directly adjacent tissue sections (AT8 immunohistochemistry, AT8 immunofluorescence and co-staining with a tau ligand, staining with a tau ligand alone) was ensured. Nuclei markers were selected according to their compatibility with imaging of the respective tau ligand. Whilst T726 $\left(\lambda_{\mathrm{ex}} 414 \mathrm{~nm} ; \lambda_{\mathrm{em}}\right.$ $500 \mathrm{~nm})$ was imaged in conjunction with DAPI $\left(\lambda_{\text {ex }}\right.$ $358 \mathrm{~nm} ; \lambda_{\mathrm{em}} 461 \mathrm{~nm}$ ), the excitation maxima of DAPI and THK-5117 $\left(\lambda_{\text {ex }} 362 \mathrm{~nm} ; \lambda_{\text {em }} 510 \mathrm{~nm}\right)$ were too close to allow for separate micrographs to be taken, and therefore, the neuronal nuclei marker Nissl Neurotrace $640\left(\lambda_{\text {ex }}\right.$ $640 \mathrm{~nm} ; \lambda_{\mathrm{em}} 660 \mathrm{~nm}$ ) was used.

\section{Fluorescent immunohistochemical co-staining with tau tracers}

Tissue sections were treated as described above. An additional blocking step before the addition of milk was used to reduce endogenous peroxidase activity, using methanol containing $0.3 \%$ hydrogen peroxide. Sections were incubated with the respective primary antibody, AT8 (Thermoscientific, 1:600), AT100 (Thermoscientific, 1:500), AT180 (Thermoscientific, 1:500), PHF1 (source: Peter Davies; 1:500) or A $\beta$-XP (Cell Signaling, 1:200), prior to tracer labelling. Incubation with a secondary biotinylated antibody (either rabbit anti-mouse IgG or swine anti-rabbit IgG; Dako, 1:200, $30 \mathrm{~min}$ ) was followed by treatment with avidin-biotin complex (Vector Laboratories; $30 \mathrm{~min}$ ). Tyramine signal amplification (red or green; 1:200) was used as a substrate for horseradish peroxidase. Sections were mounted with either DAPI-containing fluorescent mounting medium or Nissl Neurotrace 640, as described above.

\section{Fluorescence imaging}

Fluorescence imaging was performed on a Leica epifluorescent microscope. Z-stacks of images were taken with a $63 \times$ oil objective. Fluorescent images were observed within specific wavelengths for maximal excitation and emission of each fluorophore. Images were subjected to three-dimensional (3D) deconvolution with the Leica LASAF image processing software. Deconvolution parameters used the Blind Method, detecting X, Y and $\mathrm{Z}$ volumes, with 5 iterations of each $\mathrm{Z}$-stack in each fluorescent channel. Using the same software, deconvoluted images were subjected to $3 \mathrm{D}$ projection processing, producing the final image of tau tracer and antibody binding fluorescence, as average $2 \mathrm{D}$ projected images of the original $\mathrm{z}$-stack. Frequencies of fluorescent tau ligands binding to protein aggregates were semiquantitatively recorded as 'very high, 'high', 'moderate', 'low', and 'absent', relating to pathological tau load determined by AT8 immunohistochemistry in directly adjacent tissue sections. Morphological characteristics of tau inclusions were used to differentiate pre-tangles, neurofibrillary tangles and ghost tangles. Pre-tangles were defined by their immature, small, amorphous and loosely compacted perinuclear structure [45]. Neurofibrillary tangles were classified by their larger and more densely packed mature fibrillar structure that clearly delineated the cytosolic neuronal compartments. Ghost tangles cannot reliably be detected by fluorescence microscopy; they are distinguished from neurofibrillary tangles by their lack of a nucleus and stainable 
cytoplasm as depicted by haemotoxylin and eosin, or by reactivity to silver. Both of these staining methods rely on detection by light microscopy [5]. Given their specific morphological characteristics, tau aggregates could clearly be differentiated from lipofuscin pigment granules, which were observed during fluorescent tracer imaging (this is pertaining to the comparably long exposure times required for imaging of T726 and THK5117). The lipofuscin triggered fluorescence was not taken into account during the semi-quantitative assessment of tracer binding to tau pathology.

\section{Synthesis of compounds and radiolabelling}

Flortaucipir was synthesised in house following previously published synthetic routes [43], whilst the fluorescent analogue T726 was obtained through custom synthesis (AFChemPharm). THK-5117, and the labelling precursor THK-5119 were kindly provided by Prof N. Okamura, Department of Pharmacology, Tohoku University School of Medicine, Japan.

$\left[{ }^{18} \mathrm{~F}\right] \mathrm{THK}-5117$ was prepared as described previously [29]. Briefly, fluoride-18 was dissolved in $0.5 \mathrm{ml}$ of a solution of potassium carbonate $(15 \mathrm{mM})$ and Kryptofix $(30 \mathrm{mM})$ in acetonitrile containing $15 \%$ water. The mixture was dried under a stream of nitrogen at $90{ }^{\circ} \mathrm{C}$, followed by azeotropic drying with two subsequent additions of acetonitrile $(0.5 \mathrm{ml})$. The labelling precursor THK-5119, dissolved in dimethyl sulfoxide $(2 \mathrm{mg}$ in 0 . $5 \mathrm{ml}$ ), was added, and the resulting mixture stirred at $110{ }^{\circ} \mathrm{C}$ for ten minutes. Hydrochloric acid $(3 \mathrm{M}, 0.5 \mathrm{ml})$ was added, and stirring was continued for five minutes. The reaction was quenched using sodium hydroxide (1 M, $1 \mathrm{ml}$ ) under cooling (ice bath). The radioactive product was purified on a semi-preparative Chromolith ${ }^{\circ}$ Performance RP-18e column (Merck Millipore; $100 \times 4$. $6 \mathrm{~mm}$ ) at a flow rate of $5 \mathrm{ml} / \mathrm{min}$, using a mixture of water and methanol containing $0.5 \%$ trifluoroacetic acid as mobile phase. Stepwise isocratic elution with 10\% methanol in water for five minutes, followed by $38 \%$ methanol in water for ten minutes allowed isolation of the radioactive product (retention time $13 \mathrm{~min}$ ). Reformulation in tris buffered saline ( $\mathrm{pH} 7.4$, containing < $10 \%$ ethanol) was carried out on a Sep-Pak C18 Plus Light cartridge (Waters). When starting with approximately $2 \mathrm{GBq}$ of fluoride-18, $\left[{ }^{18} \mathrm{~F}\right] \mathrm{THK}-5117$ was obtained with a decay-corrected radiochemical yield (end of synthesis) of $48 \% \pm 8$, with a radiochemical purity of $>99 \%$, and with a specific activity of $6.3 \pm 1.2 \mathrm{GBq} /$ $\mu \mathrm{mol}$.

\section{Quantitative phosphorimaging}

Thawed and air-dried sections $(10 \mu \mathrm{m})$ from flash frozen tissue were post-fixed in methanol $(20 \mathrm{~min})$, rehydrated in tris buffered saline $(30 \mathrm{~min})$ and incubated with a solution of $\left[{ }^{18} \mathrm{~F}\right] \mathrm{THK}-5117$ in tris buffered saline (2 $\mathrm{MBq} / \mathrm{ml})$ for $15 \mathrm{~min}$ (1 $\mathrm{ml}$ per slide). After incubation, unbound $\left[{ }^{18} \mathrm{~F}\right] \mathrm{THK}-5117$ was removed by washing the sections in water (five minutes) and 50\% ethanol (five minutes). Internal standards were prepared by serial dilution of the $\left[{ }^{18} \mathrm{~F}\right] \mathrm{THK}-5117$ solution that was used for the incubation of the brain sections. Brain sections, and internal standards absorbed on filter paper, were left to air-dry and subsequently exposed to a phosphor screen (BAS-IP MS, GE Healthcare) overnight. Phosphorimaging was performed on a Typhoon Trio scanner (GE Healthcare), at a resolution of $50 \mu \mathrm{m}$.

For blocking studies, sections were rehydrated in tris buffered saline containing chlorgiline and L-deprenyl (1 $\mu \mathrm{M}$ each). Incubation with $\left[{ }^{18} \mathrm{~F}\right] \mathrm{THK}-5117$ was carried out under concomitant addition of different concentrations of either non-labelled THK-5117 or flortaucipir.

Phosphor images were analysed using the software ImageJ (version 1.48) [38]. Quantification of $\left[{ }^{18} \mathrm{~F}\right]$ THK-5117 binding in manually drawn regions of interest (mean \pm standard deviation in $\mathrm{kBq} / \mathrm{cm}^{2}$ ) was based on correlation curves generated from the internal standards.

\section{Nuclear emulsion autoradiography}

Sections were treated with $\left[{ }^{18} \mathrm{~F}\right] \mathrm{THK}-5117$ as described above (Phosphorimaging). After tracer incubation, the air-dried sections were dipped in nuclear photographic emulsion K.5 (Ilford; 1:4 dilution in water) and exposed overnight under exclusion of light. Slides were washed in phenisol developer (Ilford; $20 \%$, four minutes), acetic acid (1\%, two minutes), hypam fixative solution (Ilford; 20\%, four minutes) and water. Immunohistochemistry was subsequently performed as described above. The concentration of the primary antibodies was as follows: AT8 (Thermoscientific; 1:100), A $\beta-X P$ (Cell Signalling; 1:100) and PHF-1 (source: Peter Davies; 1:100). Immunostaining controls not subject to silver dipping were carried out on adjacent tissue sections.

Nuclear emulsion autoradiography photomicrographs were assessed for accumulation of silver clusters over entire areas of brain tissue for each case assessed, including grey and white matter.

\section{Results}

\section{Case characterisation}

The human post-mortem brain tissue used for this study was characterised using immunohistochemistry with the phospho-tau selective antibody AT8. Control cases had absent (Braak \& Braak stage 0), or mild tau pathology (Braak \& Braak stage I-III) in the medial temporal lobe. 
Alzheimer's disease cases were classified as Braak \& Braak stage VI and had pronounced tau pathology in the grey matter accounting for $25-35 \%$ of the surface of the respective flash frozen tissue sections (Fig. 1). In all Alzheimer's disease cases, dense neurofibrillary tangles, pre-tangles, as well as a meshwork of neuropil threads were observed in all brain areas investigated (Fig. 1a-d). In the FTDP-17 cases, small neurofibrillary tangles and abundant threads were identified (Fig. 1e and Additional file 1: Figure S1). Pick's disease cases displayed Pick's bodies in the cortical areas. Cases with progressive supranuclear palsy had pretangles, globose tangles, tufted astrocytes and neuropil threads in the frontal cortex and frequent coiled bodies in the cerebellum. Frequent astrocytic plaques, globose tangles and coiled bodies were identified in the case with corticobasal degeneration (Additional file 1: Figure S1).

\section{Microscopic assessment of the nature of pathology depicted by tau ligands}

In order to assess the binding profiles of tau PET tracers from distinct compound classes, we carried out fluorescence microscopy with the carbazole T726 and the 2arylquinoline THK-5117. This revealed tracer binding to tissue from cases with Alzheimer's disease (Fig. 2-5) and the FTDP-17 case with the R406W MAPT mutation (Fig. 6), but not to cases with Pick's disease, progressive supranuclear palsy, corticobasal degeneration, and FTDP-17 with $\triangle 280 \mathrm{~K}$ or $10+16 M A P T$ mutation (Additional file 1: Figure S2). No fluorescent tracer binding was observed in the control cases; although tau inclusions were confirmed in the medial temporal lobe of control cases CTRL3 and CTRL4 that had clear signs of pathological aging (A0B1C0 and $\mathrm{A} 2 \mathrm{~B} 2 \mathrm{C} 1$, respectively), these were not depicted by T726 and THK-5117 (Additional file 1: Figure S3).

In the Alzheimer's disease cases AD1-AD4, both fluorescent tau ligands depicted neurofibrillary tangles, pretangles and neuropil threads (Fig. 2a-o and Fig. 3a-t). On selected neurofibrillary tangles, we observed fluorescent ligand binding alongside immunoreactivity with the phospho-tau specific antibody AT8 (Fig. 2p-s, Fig. 3u-x and Additional file 1: Figure S4). Overall, the fluorescent tracers bound to fewer pathological inclusions than were depicted by antibodies: following semiquantitative assessment of the fluorescence microscopy images, T726 depicted approximately $20-30 \%$ of total pathological tau burden, as determined by AT8 immunohistochemistry, whereas THK-5117 labelled $50-80 \%$ of tau inclusions. However, both T726 and THK-5117 depicted neurons that were negative not only for the phospho-tau specific antibody AT8 (Fig. 2t and Fig. 3y), but also for antibodies detecting epitopes that are typically phosphorylated at later disease stages (AT100, AT180, PHF1) and that are therefore considered to be markers for mature neurofibrillary tangles (Additional file 1: Figure S5).

The fluorescent ligands showed high variability in depicting tau pathology across Alzheimer's disease cases, despite all cases having reached Braak \& Braak stage VI and Thal phase 5. Regional differences in tracer binding were observed, yet there was no consistency in the binding pattern of the different compound classes (Fig. 4). T726 depicted low amounts of neurofibrillary tangles, pre-tangles and neuropil threads in the hippocampus, frontal and temporal cortices of case AD1. Similarly, in the case AD2, only a low percentage of neurofibrillary tangles was detected, but moderate to high degree of tracer binding to pre-tangles and threads was observed. Surprisingly, T726 binding to mature neurofibrillary tangles was absent in the cases AD3 and AD4. Pretangles and neuropil threads were identified by T726 in these cases, albeit in low amounts. Using THK-5117 in the case AD1, very high amounts of neurofibrillary tangles, pre-tangles and neuropil threads were identified in the three brain areas investigated. In this case, the tau load depicted by the fluorescent tracer was comparable to that found by immunohistochemistry with AT8 in the directly adjacent brain sections. In the case AD2, THK5117 only depicted low amounts of tau pathology, compared to those found with AT8. High, and very high, percentage of neurofibrillary tangles, pre-tangles and threads was observed throughout brain areas in the cases AD3 and AD4, respectively.

Only THK-5117 (Fig. 3z), but not T726 (Fig. 2u), visualised plaque-like structures in the Alzheimer's disease cases. Using nuclear emulsion autoradiography with $\left[{ }^{18} \mathrm{~F}\right] \mathrm{THK}-5117$, in conjunction with immunohistochemistry, the nature of these plaquelike structures was further characterised (Fig. 5). $\left[{ }^{18} \mathrm{~F}\right]$ THK-5117 binding to neurofibrillary tangles that were immunoreactive for the phospho-tau specific antibodies AT8 and PHF1 was observed in all four Alzheimer's disease cases (Fig. 5a/b). Additionally, silver clusters co-localised with dystrophic neurites surrounding the core of neuritic plaques, following the same distribution pattern that was detected with the fluorescent tracer (Fig. 5c-f). The dense silver deposits surrounded by amyloid, as indicated by A $\beta$-XP staining (Fig. $5 \mathrm{~g} / \mathrm{h}$ ), are likely to be ghost tangles or the cores of plaques.

Both T726 and THK-5117 bound to tissue from the FTDP-17 case with the R406W MAPT mutation (FTDP1), but not to cases with the $\Delta 280 \mathrm{~K}$ or the $10+16$ variant (FTDP2/3). In FTDP1 we observed fluorescent T726 and THK-5117 labelling of a high amount of neurofibrillary tangles, pre-tangles and neuropil threads in the hippocampus (Fig. 6a). In the cortical areas, both 


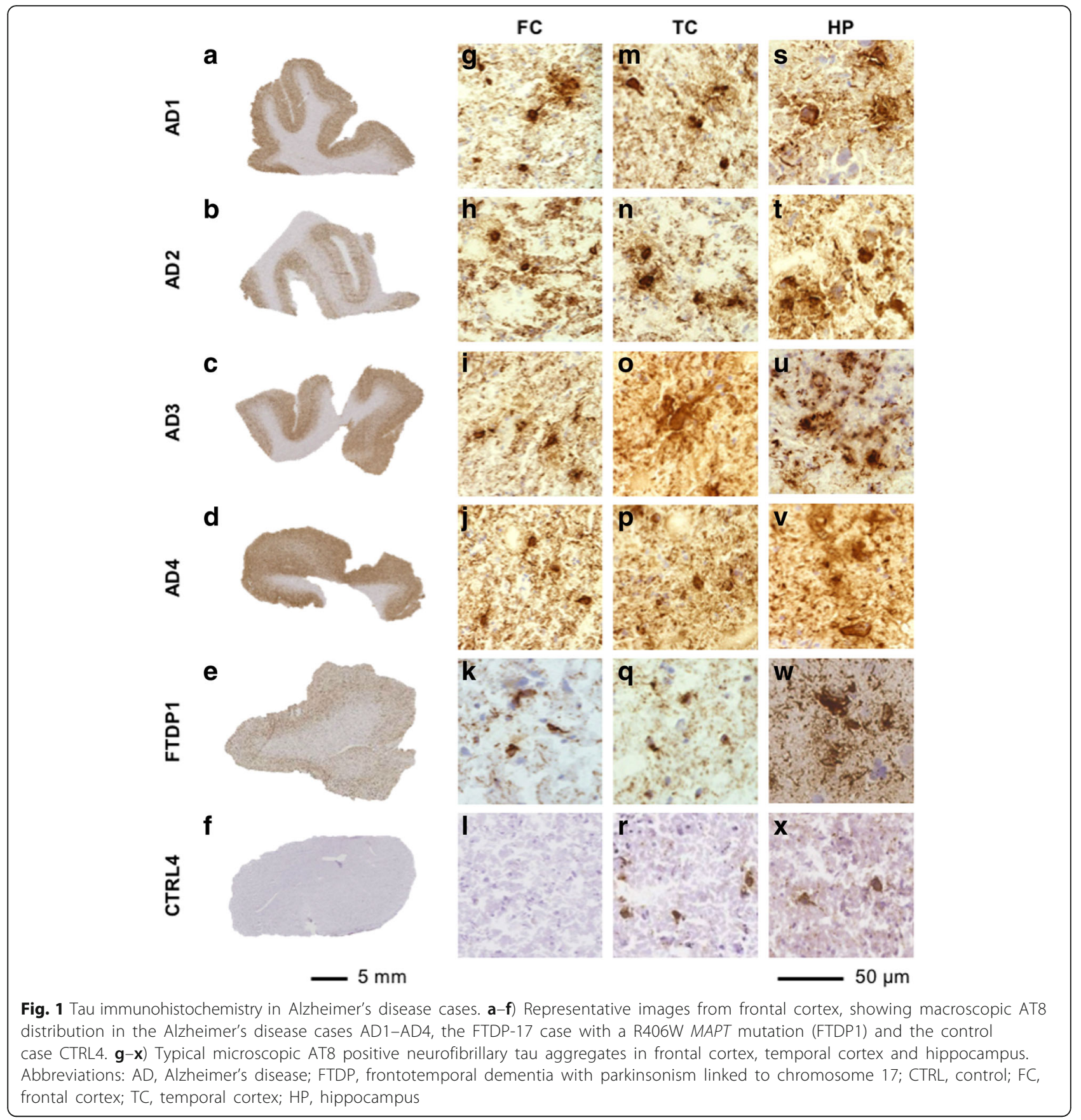

tracers depicted tau inclusions with a lower frequency. Whereas THK-5117 binding reflected pathological tau load as determined by AT8, T726 lacked binding to neurofibrillary tangles in the temporal and frontal cortices of this case (Fig. 6b).

\section{Quantitative phosphorimaging with $\left[{ }^{18} \mathrm{~F}\right] \mathrm{THK}-5117$}

In order to corroborate the high inter- and intra-case variability of tau tracer binding, as observed with fluorescent imaging, we carried out quantitative phosphorimaging with $\left[{ }^{18} \mathrm{~F}\right]$ THK-5117 in disease groups that had shown fluorescent tracer binding, i.e. Alzheimer's disease and FTDP-17, as well as control cases (Fig. 7 and Additional file 1: Figure $\mathrm{S6}$ ).

Total $\left[{ }^{18} \mathrm{~F}\right]$ THK-5117 binding (Fig. 7a) in control cases with and without brain pathology was low, ranging between 0.6 and $0.9 \mathrm{kBq} / \mathrm{cm}^{2}$ in the three brain areas investigated. In particular, there was no difference in tracer binding to the medial temporal lobe of cases with and without signs of pathological aging, despite existing pathology in the hippocampus and entorhinal cortex of the control case CTRL4 (Supporting Fig. 3). The 


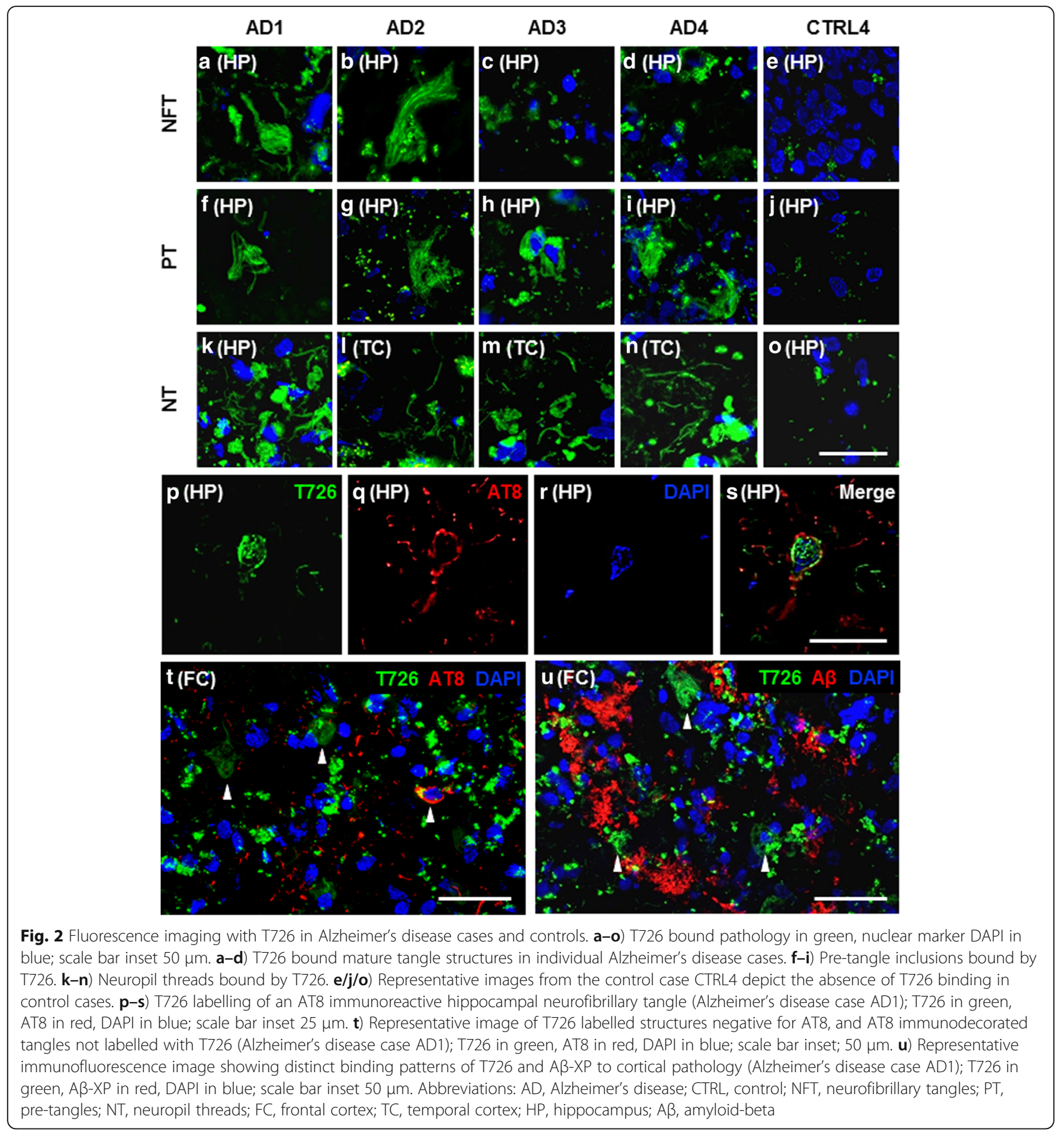

Alzheimer's disease case 1 (AD1) showed strong $\left[{ }^{18} \mathrm{~F}\right] \mathrm{THK}$ 5117 binding in the grey matter of frontal and temporal cortices as well as in the hippocampus $(9.9,7.8$ and 5 . $0 \mathrm{kBq} / \mathrm{cm}^{2}$, respectively). AD2 showed a comparably high total binding in the frontal cortex $\left(10.3 \mathrm{kBq} / \mathrm{cm}^{2}\right)$, but lower uptake in temporal cortex and hippocampus (3.8 and $1.5 \mathrm{kBq} / \mathrm{cm}^{2}$, respectively). Total binding in tissue sections of the case AD3 was approximately half of that observed in AD1, but still delineated well from control cases $\left(4.1,5.3\right.$ and $2.5 \mathrm{kBq} / \mathrm{cm}^{2}$ in frontal, temporal cortex and hippocampus, respectively). Interestingly, the case $\mathrm{AD} 4$ showed low $\left[{ }^{18} \mathrm{~F}\right] \mathrm{THK}$ 5117 binding in the frontal cortex $\left(3.2 \mathrm{kBq} / \mathrm{cm}^{2}\right)$, and particularly low uptake in temporal cortex and hippocampus (1.3 and $1.4 \mathrm{kBq} / \mathrm{cm}^{2}$, respectively). The correlation of total tau load, as determined by immunohistochemistry with the phospho-tau specific antibody AT8, and total $\left[{ }^{18} \mathrm{~F}\right] \mathrm{THK}-5117$ binding to 


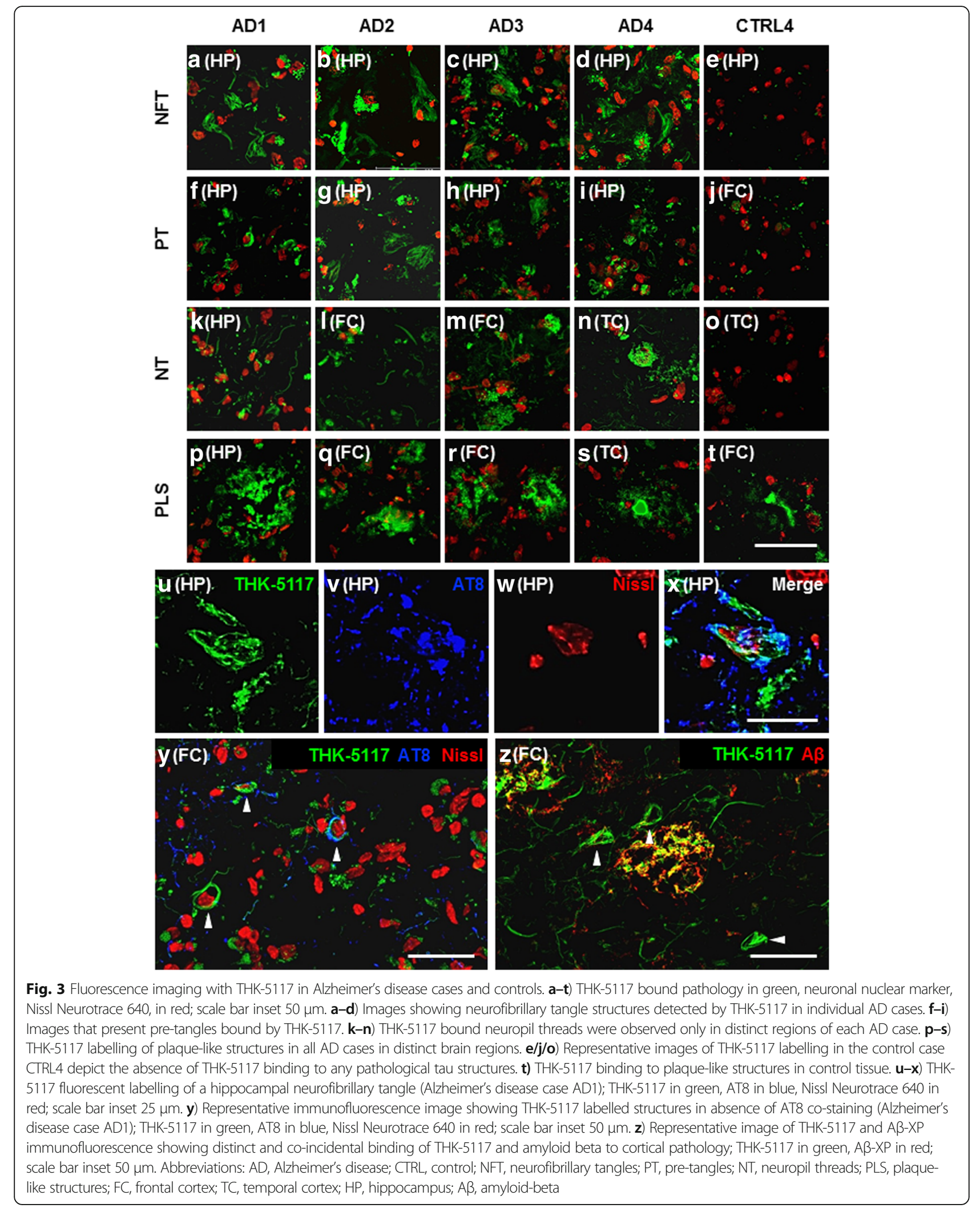




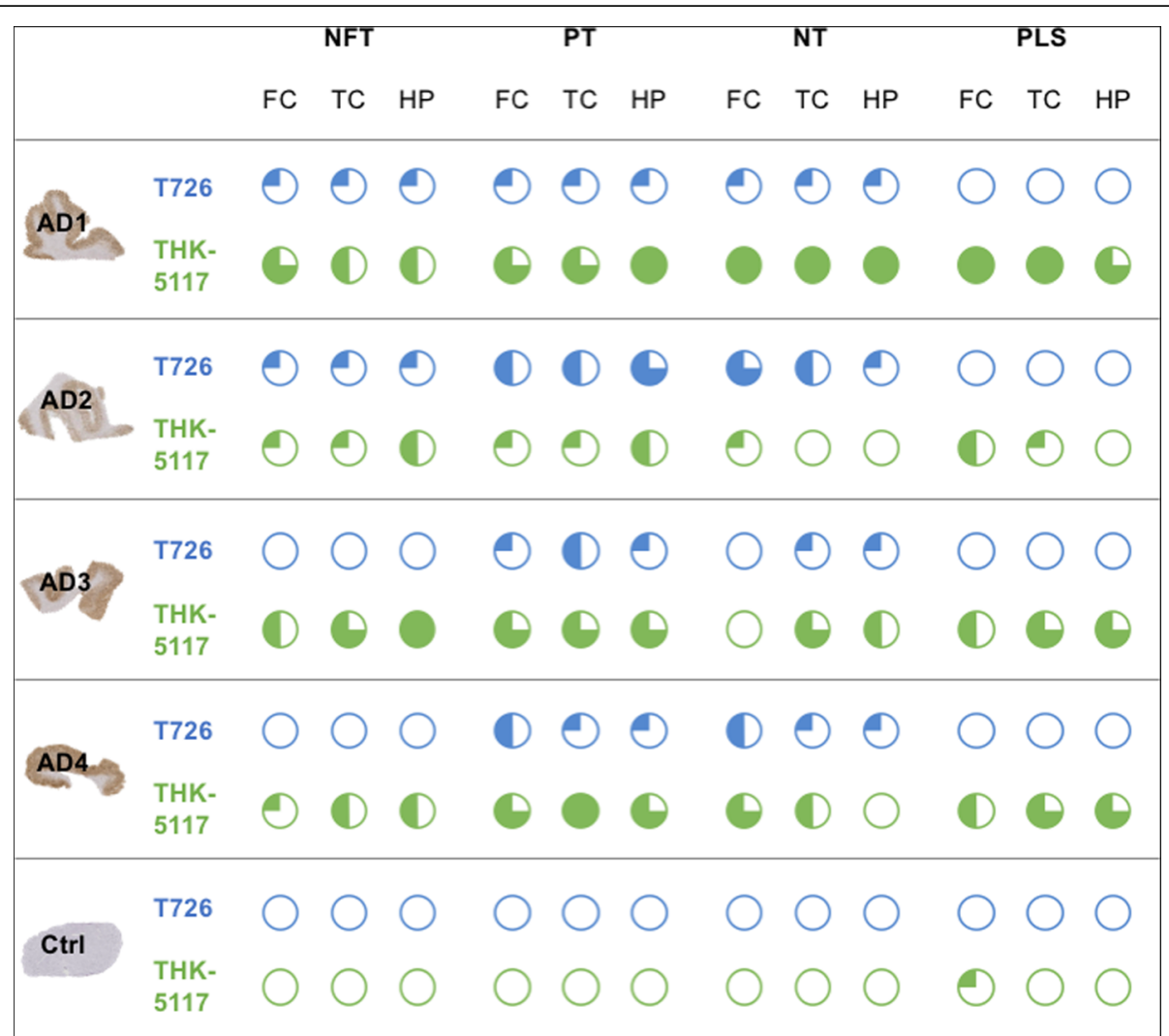

Fig. 4 Frequency of pathology depicted by T726 (blue charts) and THK-5117 (green charts) in Alzheimer's disease and control cases. Frequencies:

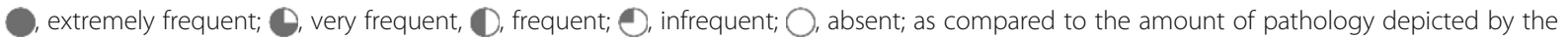
phospho-tau specific antibody AT8. Abbreviations: AD, Alzheimer's disease; Ctrl, control cases (averaged tracer uptake in normal and pathologically aged controls); NFT, neurofibrillary tangles; PT, pre-tangles; NT, neuropil threads; PLS, plaque like structures; FC, frontal cortex; TC, temporal cortex; HP, hippocampus

the grey matter of all Alzheimer's disease and control cases was low ( $\mathrm{R}^{2}$ of 0.27 ; Fig. $\left.7 \mathrm{~b}\right)$.

The FTDP-17 case harbouring the R406W mutation (FTDP1) showed slightly increased $\left[{ }^{18} \mathrm{~F}\right] \mathrm{THK}-5117$ binding in both frontal cortex and hippocampus $(1.9 \mathrm{kBq} /$ $\mathrm{cm}^{2}$ ) when compared to control cases. FTDP2 with a $10+$ 16 mutation showed similar uptake in the frontal cortex $\left(1.9 \mathrm{kBq} / \mathrm{cm}^{2}\right)$, whereas in the temporal cortex and the hippocampus of this case as well as in all brain areas of case FTDP3 $(\Delta 280 \mathrm{~K}$ mutation $)$ total binding was comparable to that in controls $\left(<1.1 \mathrm{kBq} / \mathrm{cm}^{2}\right)$.

In order to probe the specificity of the $\left[{ }^{18} \mathrm{~F}\right]$ THK- 5117 binding we carried out blocking studies to determine the degree of non-specific, as well as off-target binding, using the frontal cortex of Alzheimer's disease case AD1 (Fig. 7c). In these experiments, both isoforms of monoamine oxidases, $\mathrm{A}$ and $\mathrm{B}$, were blocked using chlorgiline and L-deprenyl, respectively, leading to an overall reduction of $\left[{ }^{18} \mathrm{~F}\right]$ THK-5117 binding from 9.9 to $6.9 \mathrm{kBq} / \mathrm{cm}^{2}$ (30\%). Non-specific $\left[{ }^{18} \mathrm{~F}\right]$ THK-5117 binding was high, and could only be reduced to $<20 \%$ of total binding when the concentration of the blocking agent exceeded 1000 times the value of the dissociation constant $\left(K_{\mathrm{d}}\right.$ of THK-5117 $\left.=5.2 \mathrm{nM}\right)$. Displacement of $\left[{ }^{18} \mathrm{~F}\right]$ THK-5117 with flortaucipir was observed in the micromolar concentration range $\left(40 \%\right.$ of total $\left[{ }^{18} \mathrm{~F}\right] \mathrm{THK}-$ 5117 binding at a blocking concentration of $1000 \times K_{\mathrm{d}}$ $(\mathrm{AV}-1451)=14.6 \mathrm{nM})$.

\section{Discussion}

Tau ligand binding in the Alzheimer's disease cases used in this study did not reflect the high, and coherent, pathological tau load as determined by immunohistochemistry. Using fluorescent as well as radiolabelled tau ligands, we observed a large inter- and intra-case variability in tracer binding, and there was no dominant or consistent uptake pattern shared by the structurally different compounds. In contrast, staining with the phospho-tau specific antibody AT8 confirmed all Alzheimer's disease cases to be affected by severe tau pathology (Braak \& Braak stage VI) throughout the brain areas investigated. In life, all cases had been diagnosed with the sporadic variant, and magnetic resonance imaging had shown generalised cortical atrophy typical for late stage disease. 

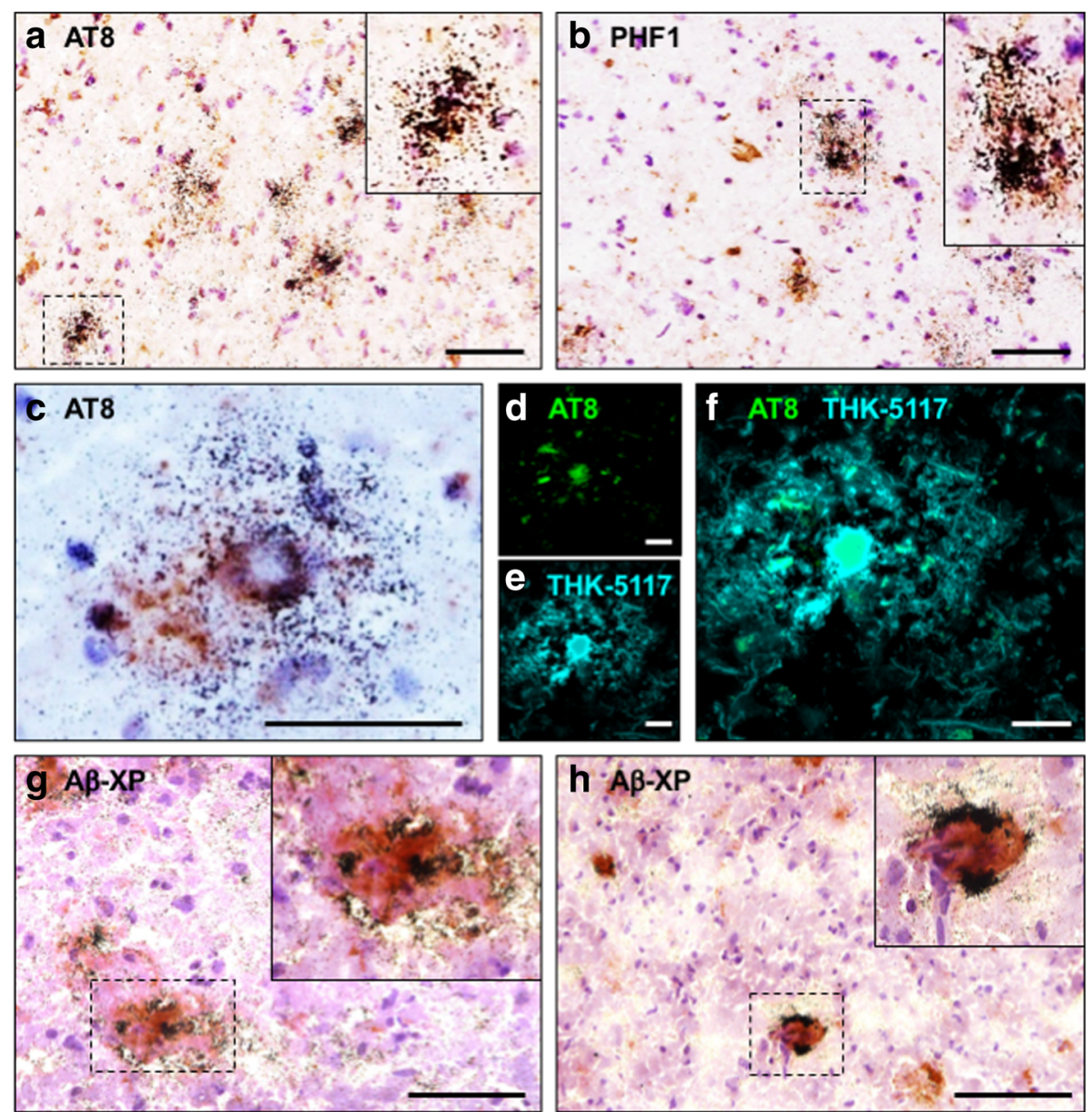

Fig. 5 Nuclear emulsion autoradiography with $\left[^{18} \mathrm{~F}\right]$ THK-5117 in the Alzheimer's disease case AD1. a/b) Silver deposition induced by $\left[{ }^{18} \mathrm{~F}\right]$ THK-5117 binding to tau inclusions co-stained with AT8 and PHF1, respectively. c-f) Neuritic plaques labelled with $\left[{ }^{18 / 19} \mathrm{~F}\right]$ THK- 5117 and co-stained with AT8. $\mathbf{g} / \mathbf{h}$ ) Neuritic tau labelled with $\left[{ }^{18}\right.$ F $]$ THK-5117 surrounding plaques visualised with the amyloid beta antibody A 3 -XP. Scale bar insets $100 \mu m$

Total $\left[{ }^{18} \mathrm{~F}\right] \mathrm{THK}-5117$ binding to the grey matter of the Alzheimer's disease cases ranged from 1.3 to $10.3 \mathrm{kBq} /$ $\mathrm{cm}^{2}$, and the lower uptake value barely delineated from that found in control tissue. In particular, one case (AD2) showed low frequency of tau pathology depicted by THK-5117 compared to that found in the other Alzheimer's disease cases, whereas the cases AD3 and AD4 appeared to be low-affinity binders for T726. Using fluorescence microscopy with THK-5117 and T726, we noted that not only the frequency, but also the type of the pathological inclusions depicted by the different compounds varied. Surprisingly, T726 binding to mature neurofibrillary tangles was only observed in the cases $\mathrm{AD} 1$ and $\mathrm{AD} 2$, but not in the cases $\mathrm{AD} 3$ and AD4; THK-5117 depicted neurofibrillary tangles with moderate to high frequency in all cases and brain areas investigated. Both tracers seemed to preferentially depict premature tau inclusions, such as pre-tangles and neuropil threads. Apart from the case AD2, i.e. the low-affinity binder for THK-5117, pre-tangles were found consistently throughout cases and brain areas using both tracers, whilst there were particular brain areas that exhibited a low frequency of threads, such as the frontal cortex of AD3 and the hippocampus of AD4. Interestingly, the 2-arylquinoline THK-5117 showed preferential binding to neuritic tau, whereas carbazole T726 binding was limited to neuronal tau. $\left[{ }^{18} \mathrm{~F}\right] \mathrm{THK}-5117$ binding was partially displaced by flortaucipir, confirming that the binding sites for the 2-arylquinoline and the carbazole overlap. Differences in the binding profile of the two compound classes may pertain to an additional binding site found for the 2-arylquinolines $[6,20]$.

The large variability in T726 and $\left[{ }^{18 / 19} \mathrm{~F}\right]$ THK-5117 binding to tissue from Alzheimer's disease cases is consistent with results from our previous study with $\left[{ }^{18} \mathrm{~F}\right]$ flortaucipir, which demonstrate a lack of correlation between tau ligand binding to post-mortem brain tissue and pathological tau load [37]. PET imaging in patients 
a
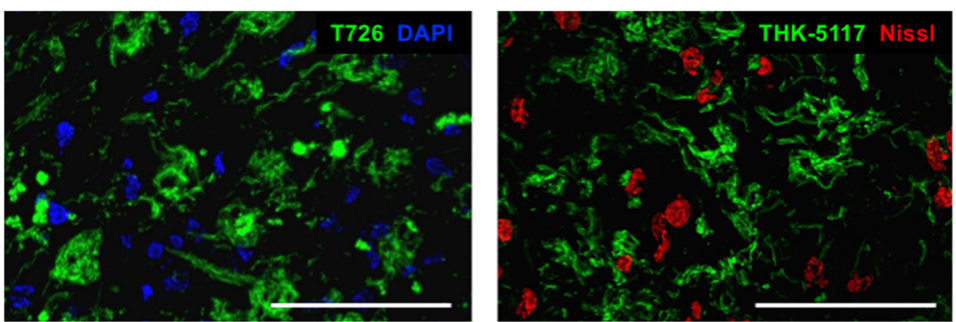

b

NFT

PT

NT

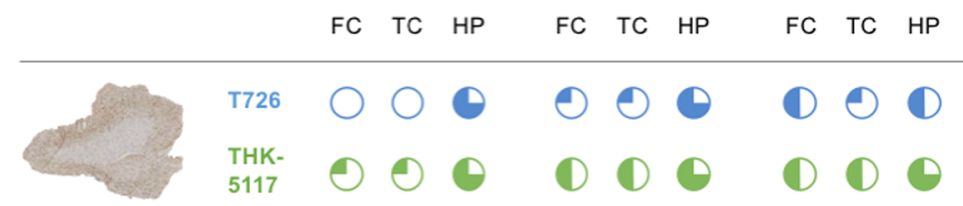

Fig. 6 T726 and THK-5117 fluorescent labelling of the FTDP-17 case with a R406W MAPT mutation. a) T726 and THK-75117 binding to the CA1 section of the hippocampus; fluorescent tracers in green, DAPI in blue, Nissl Neurotrace 640 in red; scale bar inset $100 \mu \mathrm{m}$. b) Frequencies of tau pathology depicted by the fluorescent tau ligands as compared to the amount of pathology immunodecorated by the phospho-tau specific antibody AT8. Frequencies: 0 , extremely frequent; $O$, very frequent, $D$, frequent; $O$, infrequent; $O$, absent. Abbreviations: NFT, neurofibrillary tangles; PT, pre-tangles; NT, neuropil threads; FC, frontal cortex; TC, temporal cortex; HP, hippocampus; IHC, immunohistochemistry
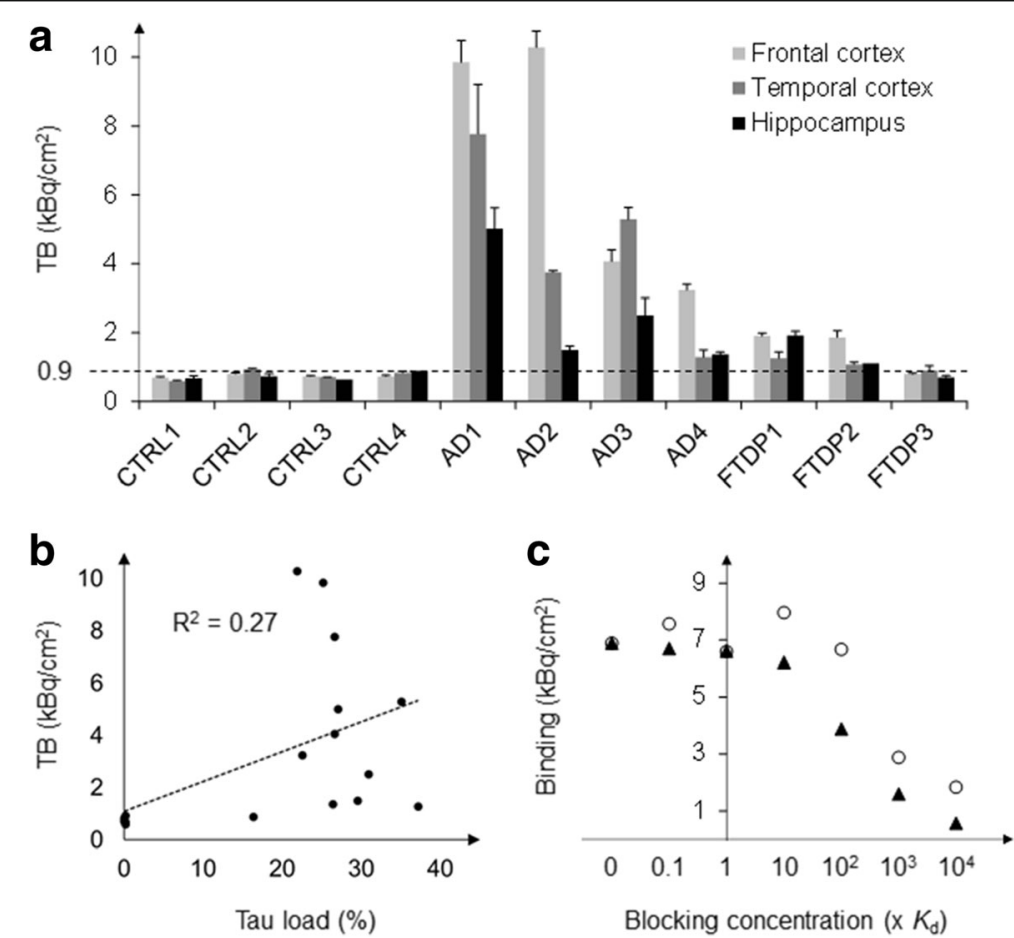

Fig. 7 Quantitative phosphorimaging with $\left[{ }^{18} \mathrm{~F}\right] \mathrm{THK}-5117$ a) Total binding of $\left[{ }^{18} \mathrm{~F}\right]$ THK-5117 to the grey matter of control and tauopathy cases. Experiments were carried out in triplicates. b) Correlation of total $\left[{ }^{18} \mathrm{~F}\right]$ THK-5117 binding in the grey matter, as determined by quantitative phosphorimaging, and tau total load, as determined by AT8 immunohistochemistry in adjacent brain sections. c) $\left[^{18} \mathrm{~F}\right]$ THK- 5117 binding to the frontal cortex of case AD1 under constant inhibition of the monoamine oxidases A and B (using $1 \mu \mathrm{M}$ chlorgylin and L-deprenyl, respectively) and with block of tracer binding using increasing concentrations of flortaucipir (circles) or THK-5117 (triangles) ranging from 0.1-10,000 times $K_{\mathrm{d}}$. Abbreviations: CTRL, control; AD, Alzheimer's disease; FTDP, frontotemporal dementia with parkinsonism linked to chromosome 17 (microtubuleassociated protein tau mutation); TB, total binding; FC, frontal cortex; TC, temporal cortex; HP, hippocampus 
with Alzheimer's disease has shown $\left[{ }^{18} \mathrm{~F}\right]$ flortaucipir binding to be closely linked to brain areas affected by neurodegeneration, and tracer uptake to correlate with the degree of cognitive impairment [17, 32, 34]. However, in some Alzheimer's disease patients, who were positively tested for amyloid, $\left[{ }^{18} \mathrm{~F}\right]$ flortaucipir retention in the cortical areas was found to be low, and comparable to that observed in age-matched controls. Other study participants showed highly focal tracer binding in limited cortical areas [35]. A similar variability - despite smaller patient cohorts - was observed when using PET tracers from the THK series [13, 21]. These studies support the notion that PET tracer binding is dependent on the strain of tau pathology in the respective patient $[7,18,27]$ and that there may be populations expressing tau inclusions with a particularly high, or low, affinity to the first generation tau PET tracers.

$\left[{ }^{18} \mathrm{~F}\right]$ Flortaucipir binding was recently reported to correlate with neurofibrillary tangle load, as determined by PHF1 antibody staining in post-mortem brain tissue from cases representing the different Braak \& Braak stages (I-VI) [24]. In our hands, neither the structural analogue T726, nor the 2-arylquinoline THK-5117, depicted tau inclusions observed in the control cases with pathology (Braak \& Braak stages II and III). Furthermore, the tau tracers did not exclusively bind to neurofibrillary tangles, but predominantly to premature tau inclusions such as pre-tangles and neuropil threads (vide supra). This is in contrast to observations made by others, which support the notion that flortaucipir [22, 31] and THK-5117 [11, 12] primarily depict mature tau inclusions. Methodological differences, in particular the use of paraffin embedded tissue that requires dewaxing and antigen retrieval methods before staining, as well as inter-case variability may explain different interpretations. Given the strong evidence of our fluorescence microscopy study for tau tracer binding to both premature and mature inclusions, we used the phospho-tau specific antibody AT8 to determine total pathological tau load in the tissue used for this study, as it detects the earliest phosphorylation sites on tau, resulting in the development of neurofibrillary structures. The low sensitivity for tau inclusions in prodromal disease cases, as reflected by the ratio of pathological tau depicted by the small molecule ligands to that depicted by AT8, may preclude detection of disease in vivo at the earliest stages. Over the course of disease, maturation of the tau inclusions may affect the accessibility of the binding site(s) for tau tracers, or the avidity of binding, for instance through gradual changes to the three-dimensional structure and density of the aggregates.

In this study, we did not observe any fluorescent tau tracer binding to inclusions predominantly composed of either three- or four-repeat tau isoforms.
However, tau tracer binding was detected in the FTDP-17 case with a R406W MAPT mutation (case FTDP1), which produces pathological inclusions that closely resemble those found in Alzheimer's disease. Tau load in the hippocampus of the case FTDP1, as determined by immunohistochemistry with AT8, was comparable to that found in the Alzheimer's disease cases (ca. 30\%), whereas in the cortical areas it was considerably lower (ca. 15\%). This was corroborated using fluorescence microscopy and nuclear emulsion autoradiography. The results also reflect findings from $\left[{ }^{18} \mathrm{~F}\right]$ flortaucipir PET scans in patients with $M A P T$ mutations that cause tau inclusions with mixed three- and four-repeat pathology (R406W and V337 M) [41, 42]. Although overall tau ligand binding in patients with the R406W and V337 M variants, as well as in the case included in our study, was lower than observed in subjects and cases with Alzheimer's disease, the distribution pattern differed in that tracer uptake is highly focal (hippocampus and surrounding temporal cortex) in the mutation carriers. Therefore, the first generation tau PET tracers may be suitable for monitoring disease progression in patients who carry the mentioned MAPT mutations; however, further studies are needed to clarify the specificity of this technique. In particular, contradictory findings of flortaucipir binding to patients and cases with MAPT mutations resulting in predominantly four-repeat pathology have been reported [2, 22, 24, 37].

In summary, our results highlight the limitations of first generation tau ligands, bearing carbazole and 2 -arylquinoline core structures, for some clinical applications. In particular, the high variability of tau PET tracer binding within and between late-stage sporadic Alzheimer's disease, and the relatively low sensitivity to tau in earliest Braak stages may limit these tracers' use for early diagnosis, monitoring of disease progression or assessment of therapeutic interventions. These limitations may be overcome by the next generation of tau PET tracers. However, it remains a concern that several of the newer tracers also target the T808 binding site, and therefore may be affected by some of the drawbacks associated with the first generation tracers. Future studies in human post-mortem brain tissue are crucial to address this concern.

Our study highlights the importance of applying a range of research techniques to the non-clinical assessment of tau PET tracers. Despite the different tracer concentrations used for fluorescence and nuclear tissue imaging, the results obtained with the different techniques demonstrated the same tracer binding patterns and could therefore be used to 
obtain complementary information about the nature of tau pathology depicted by the structurally distinct tau ligands at the cellular level. Using this unique combination of nuclear imaging and histological methods allowed us to qualitatively and quantitatively assess tracer binding at different levels of resolution. Importantly, we were able to detect tracer binding patterns resembling those observed in clinical PET studies, in particular the high variability in tracer binding between and within cases and patients, respectively. In the future, novel PET tracers should be subject to rigorous non-clinical assessment before being translated into clinical studies.

\section{Additional files}

Additional file 1: Table S1. Extended demographic data of cases included in the study. Figure S1. Tau immunohistochemistry in cases with primary tauopathies. Figure S2. Lack of fluorescent tau tracer binding in cases with primary tauopathies. Figure S3. Lack of tau tracer binding to the medial temporal lobe of control cases CTRL1-CTRL4 with and without tau pathology. Figure S4. Representative immunofluorescence images showing AT8 immunoreactive tau inclusions depicted by fluorescent tau tracers. Figure S5. Concomitant labelling of tissue from Alzheimer's disease cases with fluorescent tau tracers and phospho-tau specific antibodies. Figure S6. Quantitative phosphorimaging with $\left[{ }^{18} \mathrm{~F}\right] \mathrm{THK}-5117$. (PDF $2092 \mathrm{~kb}$ )

\section{Acknowledgements}

We thank Prof Nobuyuki Okamura (Department of Pharmacology, Tohoku University School of Medicine, Japan) for kindly providing THK-5117 and the respective labelling precursor, and Prof Peter Davies for gifting the antibody PHF1. We are grateful to Prof Nick C Fox (Dementia Research Centre, Institute of Neurology, University College London, UK) for his support of the study, and his advice on the manuscript.

\section{Funding}

We acknowledge funding by the Leonard Wolfson Experimental Neurology Centre (MCW, KS), Alzheimer's Research UK Senior Fellowship (TL) and the NIHR Queen Square Dementia Biomedical Research Unit. This work was undertaken at UCLH/UCL, which is funded in part by the Department of Health's NIHR Biomedical Research Centres funding scheme. The Queen Square Brain Bank is supported by the Reta Lila Weston Institute for Neurological Studies and the Progressive Supranuclear Palsy (Europe) Association.

\section{Authors' contributions}

$T L, E \AA$ and KS conceptualised the study. TL selected the cases included in the study. MCW conducted immunohistochemistry and fluorescence imaging experiments. MCW and KS carried out phosphorimaging and nuclear emulsion autoradiography. MCW, TL and KS analysed the data. MCW and KS wrote the manuscript. All authors read and approved the final manuscript.

\section{Ethics approval and consent to participate}

Ethical approval for the collection of post-mortem human brain tissue was obtained by the Queen Square Brain Bank for Neurological Disorders from the National Research Ethics Service Committee London (Central: 08/H0718/ $54+5)$. No personalised consent for publication was obtained as cases were anonymised for the purposes of reporting the results of this study.

\section{Competing interests}

The authors declare that they have no competing interests.

\section{Publisher's Note}

Springer Nature remains neutral with regard to jurisdictional claims in published maps and institutional affiliations.

\section{Author details}

${ }^{1}$ Institute of Nuclear Medicine and Department of Chemistry, University College London, London, UK. ${ }^{2}$ Institute of Neurology, Department of Molecular Neuroscience, Queen Square Brain Bank for Neurological Disorders, University College London, London, UK. ${ }^{3}$ Radiochemistry, University College London, Kathleen Lonsdale Building, 5 Gower Place, London WC1E 6BS, UK.

Received: 13 April 2018 Accepted: 14 April 2018

Published online: 01 May 2018

References

1. Arriagada PV, Growdon JH, Hedley-Whyte ET, Hyman BT (1992) Neurofibrillary tangles but not senile plaques parallel duration and severity of Alzheimer's disease. Neurology 42(3):631-639. https://doi.org/10.1212/ WNL.42.3.631

2. Bevan Jones WRB, Cope TE, Passamonti L, Fryer TD, Hong YT, Aigbirhio F, Kril JJ, Forrest SL, Allinson K, Coles JP, Jones PS, Spillantini MG, Hodges JR, O'Brien JT, Rowe JB (2016) [ $\left.{ }^{18} \mathrm{~F}\right] \mathrm{AV}$-1451 PET in behavioural variant frontotemporal dementia due to MAPT mutation. Ann Clin Transl Neurol 3(12):940-947 https://doi.org/10.1002/acn3.366

3. Bischof GN, Endepols H, van Eimeren T, Drzezga A (2017) Tau-imaging in neurodegeneration. Methods 130:114-123 https://doi.org/10.1016/j.ymeth. 2017.08.003

4. Braak H, Braak E (1991) Neuropathological stageing of Alzheimer-related changes. Acta Neuropathol 82(4):239-259 https://doi.org/10.1007/ BF00308809

5. Braak H, Braak E (1994) Morphological criteria for the recognition of Alzheimer's disease and the distribution pattern of cortical changes related to this disorder. Neurobiol Aging 15(3):355-356 https://doi.org/10.1016/ 0197-4580(94)90032-9

6. Cai L, Qu B, Hurtle BT, Dadiboyena S, Diaz-Arrastia R, Pike WW (2016) Candidate PET radioligand development for neurofibrillary tangles: two distinct radioligand binding sites identified in postmortem Alzheimer's disease brain. ACS Chem Neurosci 7(7):897-911 https://doi.org/10.1021/ acschemneuro.6b00051

7. Castillo-Carranza DL, Guerrero-Muñoz MJ, Sengupta U, Gerson JE (in press) Kayed R (2018) a-Synuclein oligomers induce a unique toxic tau strain. Biol Psychiatry https://doi.org/10.1016/j.biopsych.2017.12.018

8. Dickson DW, Hauw JJ, Agid Y, Litvan I (2011) Progressive supranuclear palsy and corticobasal degeneration. In: Dickson DW, Weller RO (eds) Neurodegeneration: the molecular pathology of dementia and movement disorders. Wiley-Blackwell, City, pp 135-155 https://doi.org/10.1002/ 9781444341256

9. Gobbi LC, Knust H, Körner M, Honer M, Czech C, Belli S, Muri D, Edelmann MR, Hartung T, Erbsmehl I, Grall-Ulsemer S, Koblet A, Rueher M, Steiner S, Ravert HT, Mathews WB, Holt DP, Kuwabara H, Valentine H, Dannals RF, Wong DF, Borroni E (2017) Identification of three novel radiotracers for imaging aggregated tau in Alzheimer's disease with positron emission tomography. J Med Chem 60(17):7350-7370 https://doi.org/10.1021/acs. jmedchem.7b00632

10. Goedert M, Jakes R, Vanmechelen E (1995) Monoclonal antibody AT8 recognises tau protein phosphorylated AT both serine 202 and threonine 205. Neurosci Lett 189(3):167-169 https://doi.org/10.1016/03043940(95)11484-E

11. Harada R, Okamura N, Furumoto S, Furukawa K, Ishiki A, Tomita N, Hiraoka K, Watanuki S, Shidahara M, Miyake M, Ishikawa Y, Matsuda R, Inami A Yoshikawa T, Tago T, Funaki Y, Iwata R, Tashiro M, Yanai K, Arai H, Kudo Y (2015) [(18)F]THK-5117 PET for assessing neurofibrillary pathology in Alzheimer's disease. Eur J Nucl Med Mol Imaging 42(7):1052-1061 https:// doi.org/10.1007/s00259-015-3035-4

12. Harada R, Okamura N, Furumoto S, Furukawa K, Ishiki A, Tomita N, Tago T, Hiraoka K, Watanuki S, Shidahara M, Miyake M, Ishikawa Y, Matsuda R, Inami A, Yoshikawa T, Funaki Y, Iwata R, Tashiro M, Yanai K, Arai H, Kudo Y (2016) ${ }^{18} \mathrm{~F}-\mathrm{THK} 5351$ : a novel PET radiotracer for imaging neurofibrillary pathology in Alzheimer disease. J Nucl Med 57(2):208-214 https://doi.org/10.2967/ jnumed.115.164848 
13. Harada R, Okamura N, Furumoto S, Tago T, Yanai K, Arai H, Kudo Y (2016) Characteristics of tau and its ligands in PET imaging. Biomol Ther 6(1):7 https://doi.org/10.3390/biom6010007

14. Haroutunian V, Davies P, Vianna C, Buxbaum JD, Purohit DP (2007) Tau protein abnormalities associated with the progression of Alzheimer disease type dementia. Neurobiol Aging 28(1):1-7 https://doi.org/10.1016/j. neurobiolaging.2005.11.001

15. Hostetler ED, Walji AM, Zeng Z, Miller P, Bennacef I, Salinas C, Connolly B, Gantert L, Haley H, Holahan M, Purcell M, Riffel K, Lohith TG, Coleman P, Soriano A, Ogawa A, Xu S, Zhang X, Joshi E, Della Rocca J, Hesk D, Schenk DJ, Evelhoch JL (2016) Preclinical characterization of ${ }^{18} \mathrm{~F}-\mathrm{MK}$-6240, a promising PET tracer for in vivo quantification of human neurofibrillary tangles. J Nucl Med 57(10):1599-1606 https://doi.org/10.2967/jnumed.115.171678

16. Ishiki A, Harada R, Okamura N, Tomita N, Rowe CC, Villemagne VL, Yanai $K$, Kudo Y, Arai H, Furumoto S, Tashiro M, Furukawa K (2017) Tau imaging with $\left[{ }^{18} \mathrm{~F}\right]$ THK-5351 in progressive supranuclear palsy. Eur J Neurol 24(1):130-136 https://doi.org/10.1111/ene.13164

17. Johnson KA, Schultz A, Betensky RA, Becker JA, Sepulcre J, Rentz D, Mormino E, Chhatwal J, Amariglio R, Papp K, Marshall G, Albers M, Mauro S, Pepin L, Alverio J, Judge K, Philiossaint M, Shoup T, Yokell D, Dickerson B, Gomez-Isla T, Hyman B, Vasdev N, Sperling R (2016) Tau positron emission tomographic imaging in aging and early Alzheimer disease. Ann Neurol 79(1):110-119 https://doi.org/10.1002/ana.24546

18. Kaufman SK, Sanders DW, Thomas TL, Ruchinskas AJ, Vaquer-Alicea J, Sharma AM, Miller TM, Diamond MI (2016) Tau prion strains dictate patterns of cell pathology, progression rate, and regional vulnerability in vivo. Neuron 92(4):796-812 https://doi.org/10.1016/j.neuron.2016.09.055

19. Lashley T, Rohrer JD, Bandopadhyay R, Fry C, Ahmed Z, Isaacs AM, Brelstaff JH, Borroni B, Warren JD, Troakes C, King A, Al-Saraj S, Newcombe J, Quinn N, Ostergaard K, Schrøder HD, Bojsen-Møller M, Braendgaard H, Fox NC, Rossor MN, Lees AJ, Holton JL, Revesz T (2011) A comparative clinical, pathological, biochemical and genetic study of fused in sarcoma proteinopathies. Brain 134(Pt 9):2548-2564 https://doi.org/10.1093/brain/ awr 160

20. Lemoine L, Saint-Aubert L, Marutle A, Antoni G, Eriksson JP, Ghetti B Okamura N, Nennesmo I, Gillberg PG, Nordberg A (2015) Visualization of regional tau deposits using ${ }^{3} \mathrm{H}$-THK5117 in Alzheimer brain tissue. Acta Neuropathol Commun 3(40) https://doi.org/10.1186/s40478-015-0220-4

21. Lockhart SN, Baker SL, Okamura N, Furukawa K, Ishiki A, Furumoto S, Tashiro M, Yanai K, Arai H, Kudo Y, Harada R, Tomita N, Hiraoka K, Watanuki S, Jagust WJ (2016) Dynamic PET measures of tau accumulation in cognitively normal older adults and Alzheimer's disease patients measured using $\left[{ }^{18} \mathrm{~F}\right]$ THK-5351. PLoS One 11(6):e0158460 https://doi.org/10.1371/journal. pone. 0158460

22. Lowe VJ, Curran G, Fang P, Liesinger AM, Josephs KA, Parisi JE, Kantarci K, Boeve BF, Pandey MK, Bruinsma T, Knopman DS, Jones DT, Petrucelli L, Cook CN, Graff-Radford NR, Dickson DW, Petersen RC, Jack CR Jr, Murray ME (2016) An autoradiographic evaluation of AV-1451 tau PET in dementia. Acta Neuropathol Commun 4(1):58 https://doi.org/10.1186/s40478-016-0315-6

23. Marquié $M$, Normandin MD, Vanderburg CR, Costantino IM, Bien EA, Rycyna LG, Klunk WE, Mathis CA, Ikonomovic MD, Debnath ML, Vasdev N, Dickerson BC, Gomperts SN, Growdon JH, Johnson KA, Frosch MP, Hyman BT, GómezIsla T (2015) Validating novel tau positron emission tomography tracer [F18]-AV-1451 (T807) on postmortem brain tissue. Ann Neurol 78(5):787-800 https://doi.org/10.1002/ana.24517

24. Marquié M, Normandin MD, Meltzer AC, Siao Tick Chong M, Andrea NV, Antón-Fernández A, Klunk WE, Mathis CA, Ikonomovic MD, Debnath M, Bien EA, Vanderburg CR, Costantino I, Makaretz S, DeVos SL, Oakley DH, Gomperts SN, Growdon JH, Domoto-Reilly K, Lucente D, Dickerson BC, Frosch MP, Hyman BT, Johnson KA, Gómez-Isla T (2017) Pathological correlations of [F-18]-AV-1451 imaging in non-alzheimer tauopathies. Ann Neurol 81(1):117-128 https://doi.org/10.1002/ana.24844

25. Mirra SS, Heyman A, McKeel D, Sumi SM, Crain BJ, Brownlee LM, Vogel FS, Hughes JP, van Belle G, Berg L, neurologists p CERAD (1991) The consortium to establish a registry for Alzheimer's disease (CERAD). Part II. Standardization of the neuropathologic assessment of Alzheimer's disease. Neurology 41(4):479-486 https://doi.org/10.1212/WNL.41.4.479

26. Montine TJ, Phelps CH, Beach TG, Bigio EH, Cairns NJ, Dickson DW, Duyckaerts C, Frosch MP, Masliah E, Mirra SS, Nelson PT, Schneider JA, Thal DR, Trojanowski JQ, Vinters HV, Hyman BT, National Institute on Aging; Alzheimer's Association (2012) National Institute on Aging-Alzheimer's
Association guidelines for the neuropathologic assessment of Alzheimer's disease: a practical approach. Acta Neuropathol 123(1):1-11 https://doi.org/ 10.1007/s00401-011-0910-3

27. Narasimhan S, Guo JL, Changolkar L, Stieber A, McBride JD, Silva LV, He Z Zhang B, Gathagan RJ, Trojanowski JQ, Lee VMY (2017) Pathological tau strains from human brains recapitulate the diversity of tauopathies in nontransgenic mouse brain. J Neurosci 37(47):11406-11423 https://doi.org/ 10.1523/JNEUROSCI.1230-17.2017

28. Ng KP, Pascoal TA, Mathotaarachchi S, Therriault J, Kang MS, Shin M, Guiot MC, Guo Q, Harada R, Comley RA, Massarweh G, Soucy JP, Okamura N, Gauthier S, Rosa-Neto P (2017) Monoamine oxidase B inhibitor, selegiline, reduces ${ }^{18} \mathrm{~F}$-THK5351 uptake in the human brain. Alzheimers Res Ther 9(1): 25 https://doi.org/10.1186/s13195-017-0253-y

29. Okamura N, Furumoto S, Harada R, Tago T, Yoshikawa T, Fodero-Tavoletti M, Mulligan RS, Villemagne VL, Akatsu H, Yamamoto T, Arai H, Iwata R, Yanai K, Kudo Y (2013) Novel ${ }^{18}$ F-labeled arylquinoline derivatives for noninvasive imaging of tau pathology in Alzheimer disease. J Nucl Med 54(8):1420-1427 https://doi.org/10.2967/jnumed.112.117341

30. Okamura N, Harada R, Furumoto S, Arai H, Yanai K, Kudo Y (2014) Tau PET imaging in Alzheimer's disease. Curr Neurol Neurosci Rep 14(11):500 https:// doi.org/10.1007/s11910-014-0500-6

31. Ono M, Sahara N, Kumata K, Ji B, Ni R, Koga S, Dickson DW, Trojanowski JQ, Lee VM, Yoshida M, Hozumi I, Yoshiyama Y, van Swieten JC, Nordberg A, Suhara T, Zhang MR, Higuchi M (2017) Distinct binding of PET ligands PBB3 and AV-1451 to tau fibril strains in neurodegenerative tauopathies. Brain 140(3):764-780 https://doi.org/10.1093/brain/aww339

32. Ossenkoppele R, Schonhaut DR, Schöll M, Lockhart SN, Ayakta N, Baker SL, O'Neil JP, Janabi M, Lazaris A, Cantwell A, Vogel J, Santos M, Miller ZA, Bettcher BM, Vossel KA, Kramer JH, Gorno-Tempini ML, Miller BL, Jagust WJ, Rabinovici GD (2016) Tau PET patterns mirror clinical and neuroanatomical variability in Alzheimer's disease. Brain 139(Pt 5):1551-1567 https://doi.org/ 10.1093/brain/aww027

33. Passamonti L, Vázquez Rodríguez $P$, Hong YT, Allinson KS, Williamson D, Borchert RJ, Sami S, Cope TE, Bevan-Jones WR, Jones PS, Arnold R, Surendranathan A, Mak E, Su L, Fryer TD, Aigbirhio FI, O'Brien JT, Rowe JB (2017) ${ }^{18} \mathrm{~F}$-AV-1451 positron emission tomography in Alzheimer's disease and progressive supranuclear palsy. Brain 140(3):781-791 https://doi.org/10. 1093/brain/aww340

34. Phillips JS, Das SR, McMillan CT, Irwin DJ, Roll EE, Da Re F, Nasrallah IM, Wolk DA, Grossman M (2017) Tau PET imaging predicts cognition in atypical variants of Alzheimer's disease. Hum Brain Mapp:1-18 https://doi.org/10. 1002/hbm.23874

35. Pontecorvo MJ, Devous MD Sr, Navitsky M, Lu M, Salloway S, Schaerf FW, Jennings D, Arora AK, McGeehan A, Lim NC, Xiong H, Joshi AD, Siderowf A, Mintun MA; ${ }^{18}$ F-AV-1451-A05 investigators (2017) Relationships between flortaucipir PET tau binding and amyloid burden, clinical diagnosis, age and cognition. Brain 140 (3): 748-763. https://doi.org/10.1093/brain/aww334

36. Saint-Aubert L, Lemoine L, Chiotis K, Leuzy A, Rodriguez-Vieitez E, Nordberg A (2017) Tau PET imaging: present and future directions. Mol Neurodegener 12(1):19 https://doi.org/10.1186/s13024-017-0162-3

37. Sander K, Lashley T, Gami P, Gendron T, Lythgoe MF, Rohrer JD, Schott JM, Revesz T, Fox NC, Årstad E (2016) Characterization of tau positron emission tomography tracer $\left[{ }^{18} \mathrm{~F}\right] \mathrm{AV}$ - 1451 binding to postmortem tissue in Alzheimer's disease, primary tauopathies, and other dementias. Alzheimers Dement 12(11):1116-1124 https://doi.org/10.1016/j.jalz.2016.01.003

38. Schneider CA, Rasband WS, Eliceiri KW (2012) NIH image to ImageJ: 25 years of image analysis. Nat Meth 9(7):671-675 https://doi.org/10.1038/nmeth.2089

39. Schöll M, Lockhart SN, Schonhaut DR, O'Neil JP, Janabi M, Ossenkoppele R, Baker SL, Vogel JW, Faria J, Schwimmer HD, Rabinovici GD, Jagust WJ (2016) PET imaging of tau deposition in the aging human brain. Neuron 89(5):971-982 https://doi.org/10.1016/j.neuron.2016.01.028

40. Schwarz AJ, Yu P, Miller BB, Shcherbinin S, Dickson J, Navitsky M, Joshi AD, Devous MD Sr, Mintun MS (2016) Regional profiles of the candidate tau PET ligand ${ }^{18} \mathrm{~F}-\mathrm{AV}$-1451 recapitulate key features of Braak histopathological stages. Brain 139: 1539-1550. https://doi.org/10.1093/brain/aww023

41. Smith R, Puschmann A, Schöll M, Ohlsson T, van Swieten J, Honer M, Englund E, Hansson O (2016) ${ }^{18} \mathrm{~F}-\mathrm{AV}$-1451 tau PET imaging correlates strongly with tau neuropathology in MAPT mutation carriers. Brain 139: 2372-2379 https://doi.org/10.1093/brain/aww163

42. Spina S, Schonhaut DR, Boeve BF, Seeley WW, Ossenkoppele R, O'Neil JP, Lazaris A, Rosen HJ, Boxer AL, Perry DC, Miller BL, Dickson DW, Parisi JE, 
Jagust WJ, Murray ME, Rabinovici GD (2017) Frontotemporal dementia with the V337M MAPT mutation: tau-PET and pathology correlations. Neurology 88(8):758-766 https://doi.org/10.1212/WNL.0000000000003636

43. Szardenings AK, Kolb HC, Walsh JC, Chen G, Gangadharmath UB, Kasi D, Liu C, Sinha A, Wang E, Yu C, Zhang W, Chen K, Mocharla VP, Scott PJH (2012) Imaging agents for detecting neurological dysfunction. Patent Application US20120302755 A1 (Siemens Medical Solutions USA, Inc.)

44. Thal DR, Rueb U, Orantes M, Braak H (2000) Phases of a beta-deposition in the human brain and its relevance for the development of AD. Neurology 58(12):1791-1800 https://doi.org/10.1212/WNL.58.12.1791

45. Uchihara T, Nakamura A, Yamazaki M (2001) Mori O (2001) evolution from pretangle neurons to neurofibrillary tangles monitored by thiazin red combined with Gallyas method and double immunofluorescence. Acta Neuropathol 101(6):535-539 https://doi.org/10.1007/s004010000306

46. Vermeiren C, Motte P, Viot D, Mairet-Coello G, Courade JP, Citron M, Mercier J, Hannestad J, Gillard M (2018) The tau positron-emission tomography tracer AV-1451 binds with similar affinities to tau fibrils and monoamine oxidases. Mov Disord 33(2):273-281 https://doi.org/10.1002/mds.27271

47. Vettermann F, Brendel M, Schaenecker S, Haeglinger G, Danek A, Levin J, Bartenstein P, Okamura N, Rominger A (2016) [ $\left.{ }^{[8} \mathrm{F}\right]$ THK-5351 PET in patients with clinically diagnosed progressive supranuclear palsy. J Nucl Med 57 (supplement 2): 457

48. Wang Y, Mandelkow E (2016) Tau in physiology and pathology. Nat Rev Neurosci 17:5-21 https://doi.org/10.1038/nrn.2015.1

49. Xia CF, Arteaga J, Chen G, Gangadharmath U, Gomez LF, Kasi D, Lam C, Liang Q, Liu C, Mocharla VP, Mu F, Sinha A, Su H, Szardenings AK, Walsh JC, Wang E, Yu C, Zhang W, Zhao T, Kolb HC (2013) [(18)F]T807, a novel tau positron emission tomography imaging agent for Alzheimer's disease. Alzheimers Dement 9(6):666-676 https://doi.org/10.1016/j.jalz.2012.11.008

50. Zhang W, Arteaga J, Cashion DK, Chen G, Gangadharmath U, Gomez LF, Kasi D, Lam C, Liang Q, Liu C, Mocharla VP, Mu F, Sinha A, Szardenings AK, Wang E, Walsh JC, Xia C, Yu C, Zhao T, Kolb HC (2012) A highly selective and specific PET tracer for imaging of tau pathologies. J Alzheimers Dis 31(3):601-612 https://doi.org/10.3233/JAD-2012-120712

51. Zhao Z, Sagare AP, Ma Q, Halliday MR, Kong P, Kisler K, Winkler EA, Ramanathan A, Kanekiyo T, Bu G, Owens NC, Rege SV, Si G, Ahuja A, Zhu D, Miller CA, Schneider JA, Maeda M, Maeda T, Sugawara T, Ichida JK, Zlokovic BV (2015) Central role for PICALM in amyloid- $\beta$ blood-brain barrier transcytosis and clearance. Nat Neurosci 18(7):978-987 https://doi.org/10. 1038/nn.4025

\section{Ready to submit your research? Choose BMC and benefit from:}

- fast, convenient online submission

- thorough peer review by experienced researchers in your field

- rapid publication on acceptance

- support for research data, including large and complex data types

- gold Open Access which fosters wider collaboration and increased citations - maximum visibility for your research: over $100 \mathrm{M}$ website views per year

At BMC, research is always in progress.

Learn more biomedcentral.com/submissions 